the highest success in his calling the science-master must, of course, be thoroughly versed in his subject, alike theoretically and practically. He should, if possible, be a man who has himself done some original research, or at least is intimately familiar with methods of experimentation and investigation, and able to guide his pupils along the lines of independent research. I am strongly of opinion that his efficiency will be much augmented if he has had a good literary as well as a scientific training. When he enters on his teaching career he will soon find the great advantage of a cultivated style, both in discoursing and in writing. Unfortunately some able men of science who have neglected the literary side of their education cannot arrange their thoughts in proper sequence or express them with clearness and terseness. I would urge the science-master to keep his hold on literature, ancient as well as modern. Many a time when weary with his labours, and discouraged, perhaps, by the difficulties wherewith they are beset, he will find in that delightful field ample consolation and refreshment.

But, above all, the science-master must be thoroughly in love with his subject and possess the power of infusing some of his affection for it into his pupils. His evident and genial enthusiasm should be infectious and become an inspiration that appeals to his boys in everything he does, whether as he lectures and demonstrates to them in the class-room or as he shows them how to work in the laboratory. There are probably few other callings in the educational domain where the personal touch, the stimulating influence that springs from earnest devotion to a subject, has so many opportunities of manifesting itself and tells more promptly and powerfully on the pupils. The teacher who is gifted with such an inspiring power may do more in the way of developing a love of science with the meagre outfit of a parish school than a man without this influence can do with all the resources of a modern laboratory.

\section{RADIATIONS OLD AND NEW 1}

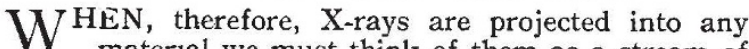
material we must think of them as a stream of separate entities, each one of which has complete independence of its neighbours and pursues a life of its own. It changes to a $\beta$ ray and back again; as a $\beta$ ray it is liable to loss of energy and much deflection, so that those rays which do not pass through the body but are held therein end as electrons moving about in the body with the velocities of thermal agitation; that is to say, with those velocities which free electrons in the body must possess on account of the share which they take in carrying the heat of the body.

Now we may ask ourselves what will be the result if transformations continue to take place at these lower energies; for the moment let us assume that they do. Let us consider some substance like a block of metal. Within it we know that there are innumerable electrons travelling to and fro with various speeds. In their motion is stored up energy; the communication of heat to the body makes them dance more quickly. When the quicker motion is begun in one part of the body, diffusion hands on the motion to the rest; that is to say, heat has been conducted through the body. If we try to pass an electric current through the body, it is the movement of the electrons that constitutes the current. This is the accepted theory at the present time. It is even pos-

1 Evening discourse delivered on September 6, 1912, before the British Association at Dundee by Prof. W. H. Bragg F.R.S. Continued from p. 532 .

NO. 2255, VOL. 90] sible-but this is not accepted by all-that the energy of the moving electrons in the body constitutes the main store of heat therein. The electrons do not all move at the same speed, of course; but there is a certain well-known distribution of their energies about a mean value. At any time a certain percentage of the electrons are moving with speeds lying within definite limits, although the individuals possessing such speeds are continually changing. If we now take into account the transformations of which I have been speaking, we find that there must be X-ray quanta-this name will do for them as well as any others-in such numbers as to be in equilibrium with the electrons of every variety of speed. In the case of the X-rays and electrons which we have been handling in our experiment, we find that the greater the energy the larger the number of $\mathrm{X}$-ray quanta required to be in equilibrium with the corresponding electrons, for quanta of large energy are transformed into electrons much more rarely than quanta of small energy, whereas electrons of large energy are transformed as often, and perhaps more often, than those of small energy. Thus the distribution of energy amongst the quanta is not the same as the distribution amongst the electrons; in the former there is a much larger number-relatively-of the quanta of larger energy.

The electrons which we are considering have very little power of penetration or of breaking away from the substances in which they are. At high temperatures, when they move more quickly, there is a considerable emission, an effect which has been much studied recently. But at ordinary temperatures the emission of electrons is small. Recently R. W. Wood has suggested that there must be an "aura" of electrons surrounding a conductor and extending a minute distance away, since only in this way can we account for the fact that electricity passes freely from one conductor to another when they are separated by a space of the order of a wave-length of light. But if the electrons have such difficulty in breaking away from a substance, this is not true of the X-ray quanta. If they behave like those we have been investigating of recent years, they have far greater powers of penetration than the electrons, and every body must be emitting them in streams. Moreover, if bodies be placed near each other, there will be an interchange which will hand energy from one to the other until there is an equilibrium. If a hot body is placed near a cold one, the former contains some electrons and corresponding quanta of great energy, and as these stream over to the cold body, they go through transformations which permit of loss of energy, since for a time they put the energy into electron carriers which can exchange, and do exchange, energies with others - through the mediation of the atoms, it may be. X-ray quanta have not that power of themselves. Thus in time the two bodies are brought to the same temperature.

In this way we have a conception of radiation which on the surface differs from that which is ordinarily held. But does it do so really? May it be that we have merely found a different method of regarding the processes of radiation? If so, that would be a very good thing, for it is one of the best aids to inquiry to have more than one hypothesis which will link together a number of experimental facts. Nor need we be afraid if the hypotheses differ considerably. On the contrary, that means that we have the greater number of interesting things to discover between the two points of view and their final point of convergence.

Now we know that when light falls upon material substances there is an emission of electrons of slow speed; in other words, light radiation resembles 
$\mathrm{X}$-radiation in one important particular. Investigators have gone further. They have shown with considerable probability that the velocity of the ejected electron varies with the wave-length of the light; the shorter the wave-length, the swifter the electron. Moreover, there are lines of reasoning, worked out in great detail by Planck, Einstein, and others, which lead to the thought that light energy is contained in separate quanta the shorter the wave-length, the more energy in the quantum. This is one of the most remarkable developments of modern physics.

It seems as if there was a strong invitation to consider radiation from this point of view. We ought not to think that in doing so we abandon the wave theory or its electro-magnetic development. Rather we might say that the radiation problem is too great to be seen all at once from any point to which we have hitherto attained, and that it is to our advantage to look at it from every side.

It would be quite fair, moreover, to say that there is something after all in the corpuscular theory of light. There is a very great deal of evidence, as I have already indicated briefly, for a corpuscular theory of X-rays; and it is widely held that the two forms of radiation are akin to each other. How can we hold a corpuscular and a wave theory of light at the same time?

If we say that radiation consists in the emission of quanta, each of which traverses space without spread ing or altering in any way, and label this a corpuscular theory; and if, on the other hand, we suppose light to consist of wave-motions, and that we can resolve such wave-motions at any one time into elements each of which might exist alone and would then spread through space like a ripple on a pond; and if we say that the quantum in the one theory is to be matched with the element in the other, then, of course, the two theories are inconsistent.

But such inconsistencies are difficulties of our own making. If one hypothesis links together a number of observed facts, and a second hypothesis a somewhat different number; and if we think the two are inconsistent, the fault must be ours. We must be stretching one or other hypothesis to breaking-point, and we must work in the hope of finding a new hypothesis of greater compass. Until we do so, we are right to use those which are more limited; it is the way of scientific advance. So the great men of the past have done, as we may see readily.

Let us go back to the discussions of the close of the seventeenth century, the time when Newton, Huygens, Hooke, Pardie, and others debated the nature and form of light. A very important discovery had recently been made by Romer, who had shown by astronomical observations that light, which brought the news of the events taking place in space, took time to bring it; in others words, that light had a velocity. Romer had even succeeded in measuring the velocity with fair accuracy. Now Descartes had supposed the propagation of light to be instantaneous. $\mathrm{He}$ had considered it to be a pressure transmitted across a plenum between the luminous object and the eye; according to a well.known image, vision resembled the process by which objects are made manifest to a blind man, who feels for them with his stick and receives pressures transmitted thereby. Apart from the direct proof by Romer that this view was wrong, a very interesting objection to it is given by Huyger s, who, after stating the Cartesian theory, remark.s that "it is impossible so to understand what I have been saying about two persons mutually seeing one another's eyes, or how two torches can illuminate each other." That is to say, it is impossible to explain on a simple pressure theory the perfect facility with which rays of light traverse each other without injury. This mutual traverse of light rays interested Huygens exceedingly, and, as we shall see, influenced materially his choice of the hypothesis in terms of which he expressed the facts known to him.

Thus Newton and Huygens were led to introduce the idea of motion of some sort of matter as a fundamental point in their theories. They did so in different ways; and the distinction grew to be a cleavage between two schools of thought. It was not a very deep distinction at first; it would have been easy to have stepped from one side to the other of the dividing line. Only in later times did the corpuscular and wave theories stand immovable in hostile antagonism. It is not at all impossible that modern research will once more draw the two theories together.

The difference may be put in this way:-Newton imagined light corpuscles which moved in straight lines from the source of light to the recipient.

thought that the "light" had the same carrier from beginning to end of its path. We should now express his idea by saying that the "energy" of the iight had the same carrier; but Newton did not, of course, conceive of light-energy as a quantity to be measured and discussed. How far he was from this more modern idea is instanced by his supposition that the radiating power of the sun was conserved by the mutual radiation of its parts.

On the other hand, Huygens imagined the light to be passed on from particle to particle of the æther; that is to say, the energy was not carried by one particle all the way, but by relays. It must be remembered that he thought of the æther as a collection of particles resembling the particles of luminous bodies, but of smaller dimensions. The latter particles he supposed to float in a subtle medium which agitated them and made them strike against the particles of the æether, which thus became the seat of spreading impulses. We might compare the difference between the ideas of Newton and Huygens with the difference between the despatch of a message by a special runner and the spreading of a rumour.

Huygens has given two reasons for his choice of hypothesis: one, the extreme speed of light, which Romer had recently found; the other, the ease with which rays of light traverse each other. These induced him to reject the idea of the movement of matter through the whole of the distance from source to receiver, since he could not imagine how matter could move with so great a speed, nor could he conceive how material rays could pass through each other. He arranged æther corpuscles in a row between source and receiver, and supposed light to move along the row in the same way that a disturbance would move along a row of glass spheres placed so as to touch each other. Indeed, he filled all space with æether particles in contact so as to allow of the transmission of disturbances from any one point to any other. In such a plenum two disturbances might easily be imagined to cross each other without hindrance. To use an illustration which he gives himself, "If against this row (B C in Fig. Io) there are pushed from two
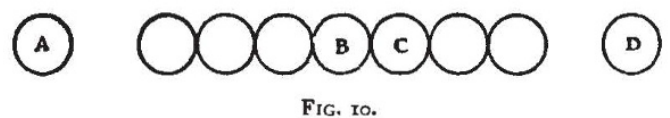

opposite sides at the same time two similar spheres $\mathrm{A}$ and $\mathrm{D}$, one will see each of them rebound with the same velocity which it had in striking; yet the whole row will remain in its place, although the movement has passed along its whole length twice over." It is, of course, the movements, not the spheres, which

NO. 2255 , VOL. 9o] 
traverse each other. Or we may arrange the experiment as in Fig. II. If the balls $A_{1}$ and $B_{1}$ are pushed in the directions of the arrows so as to strike the rows they are shown approaching, the spheres $A_{3}$ and $\mathrm{B}_{3}$ will spring forward and continue the lines of motion of $A_{1}$ and $B_{1}$, and the movements will have crossed each other without any injury. He conceived such a result to be beyond explanation on a theory like Newton's.

His hypothesis met also, as he thought, the other of the two fundamental requirements. The disturbance might be supposed to move as fast as was desired, even with the extreme velocity which light, according to Romer, possessed. For, as he says, "there is nothing to hinder us from supposing the particles of the æther to be of a substance as nearly approaching to perfect hardness and possessing a springiness as prompt as we choose." And another very important property of light was illustrated at the same time, viz., that the velocity in free æther was independent of the intensity.

It is to be observed that Huygens takes the ideas of hardness and impenetrability of matter which he has drawn from the behaviour of glass spheres and applies them to the molecules of the æother.

From what we have seen of the properties of the new rays we cannot allow Huygens any justification

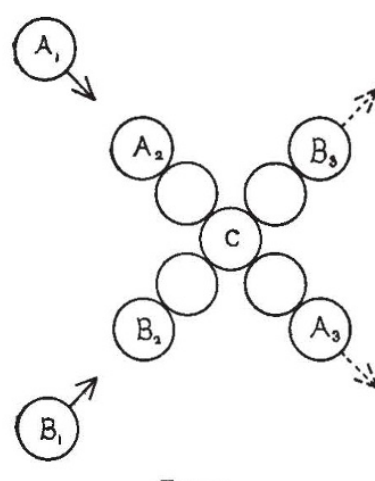
of the reasons which he gives for his preference for the wave theory. There were two, you will remember. In the first place, he supposed that matter could not move with so great a speed as light; yet you see that the $\alpha$ particles move practically as fast as he conceived light to move, and they are as mateisial as anything else. Secondly, he argued that streams of matter could not interpenetrate each other; yet we see that atoms can pass through each other easily. Indeed, the more we consider the behaviour of the rays from radio-active substances, the more impossible appears the view that "particles" of any sort have boundaries which are limits to interpenetration. We see no reason for supposing that there is anything in the known universe which can retain a portion of space to its own exclusive use and forbid all strangers to enter therein.

So the reasons which Huygens gives for his choice of a hvpothesis are both mistaken; and we might think that this was a bad beginning for the structure which he built. But his true foundation was laid otherwise. The spreading-pulse theory suggested to him his famous construction of the wave front, which has been of such immense importance in the development of our knowledge of radiation. His construction gave a correct account of the phenomena of reflection and refraction, and, what was most wonderful, he found himself able to explain by its means the complicated motion of light in Iceland spar. In this way he began the marvellous development of the relations between light and crystalline structure which has roused the interest and admiration of the subsequent centuries. It is true that he had no idea of a regular succession of waves; in fact, he expressly states that he does not wish us to think of his pulses as following each other at regular distances. He did not explain colours, and he failed altogether to account for polarisation. But his hypothesis linked certain facts together, and was useful so far as it went.

It was Newton with his corpuscular theory who introduced the idea of periodicity in order to explain the colours of the soap film and other "thin plates"; who ascribed differences in colour to differences of frequency, and correctly described the phenomena of polarisation as due to the rays of light having sides, a description which could not be applied to the conception of Huygens. Newton was able to express many of the facts known to him in terms of vibrations of an all-pervading æther; he saw that in such case the longer vibrations would excite the sensation of red, and the shorter-the more refrangible-the sensation of violet. He actually supposed that such viusdtions travelled along the optic nerves and carri-d the sensations to the brain, and he direrted attention to persistence of vision as evidence of the "vibratory, nature of the motions at the bottom of the eye." Heat he supposed to be conveyed by æther vibrations. $\mathrm{He}$ could express the behaviour of a soap film in respect to colour in terms of the wave theory with formal correctness, showing its dependence on the ratio between the thickness of the film and the wave length of light. But he preferred to express his ideas on a corpuscular model, because he could not otherwise explain the formation of sharp shadows, and deemed it impossible for a pulse on rounding a corner to spread so little as light. It was for this reason he rejected the theory of Huygens, and he was perfectly right. If we take Huygens's own model, if we project a billiard ball against a group of other balls in contact, as we might, somewhat inefficiently, start a game of pyramids, the energy of motion is scattered every way, and balls fly in all directions. Huygens never met this objection; it was not answered until the time of Fresnel, more than a hundred years afterwards. Newton was also impressed with the impossibility of varying the nature of light by transmission, reflection, or refraction, and ascribed all apparent changes of colour to sorting processes. As he says, "very small bodies conserve their properties unchanged in passing through several mediums, which is a condition of the rays of light." $\mathrm{He}$ was thinking of contemporaries who supposed that the colour of light was readily changed in deviation or transmission.

The essence of Newton's idea was the travel of light as an entity which did not spread or change as it went. He implied by the term "corporeity of light " no more than "something or other propagated every way in straight lines from luminous bodies without determining what that thing is, whether a confused mixture of difform qualities or modes of bodies, or of bodies themselves; or of any virtues, powers, or beings whatsoever." He strongly opposed a tendency to read more into his hypothesis than it was intended to hold. In these respects the X-ray resembles very closely the corpuscle which Newton conceived, so long at least as it remains untransformed. But if transformation occurs the electron generally loses energy, and a retransformed X-ray will have less energy than the original, a well-known process. It may be compared with the phenomenon of fluorescence, of which Newton knew nothing.

Now if X-rays are to be classed with light, as there are reasons for supposing, and as many do suppose with more or less conviction, then it must be acknowledged that Newton's conception has more value in it than the last century has been accustomed to grant. But we shall not therefore adopt Newton's theory as he left it. It is too obviously defective. It cannot explain diffraction, and his main reason for rejecting the wave theory was wrong. He gave no satisfactory explanation of the uniformity of the velocity of light

NO. 2255, VOL. 90] 
in space. Even his explanation of the colours of thin films is defective. Moreover, he was hopelessly at sea, and, it may be observed, so was Huygens, in attempting to explain the absorption of light. Neither of them had at his command any mechanism but that of the collisions between particles of æther, particles of matter, and light corpuscles, and they could but juggle with the relative sizes of these things. Newton was very hard put to it to explain the difference between a perfectly transparent body and a perfectly black one, and was compelled to suppose it due to a small difference in the sizes of the particles of matter. Huygens would have liked to ascribe internal reflections at the surface of a piece of glass to collisions between the æther corpuscles and the particles of air outside, and was disconcerted by the fact that reflection took place equally well when there was no air at all. But it is quite unnecessary to follow the subject further, and discuss the contributions of Young and Fresnel, and the other men of famous names to whom the modern theories of radiation are due.

The point is simply this, that each of these great workers constructed for himself a hypothesis or model, which represented correctly certain facts known to him, and by its aid was able to use what he knew as a means to learn more. The results of his work depended unon the construction of his model, and his choice of the known facts he had made it to represent to a greater or less degree. For no one could construct a hypothesis which represented correctly all that was known. But if it was correct so far as it went it led to good results in a limited field.

Therefore it happens that hypotheses must always be diversified, and it is well for the possibilities of advance that they should be. If now we have a number of new facts regarding new radiations, if it turns out that they are to be carried over to the older radiations which have been studied for so long, and if the wave theory cannot absorb them at once, this means no rejection of the work of the past, no retracing of steps. It means rather the mnriching of our opportunities of advance, in which all the good work which has been done in the past will tell as well as that which we may hope to do in the future.

If my observations are well-worn sayings, you will perhaps forgive the fact in the newness, and $I$ should like to add, if I might, the appropriateness, of the illustration. It does, after all, make for our encouragement and efficiency if we remember that we are free to make any hypothesis we please, and that we are not to be judged directly for the choice we make, but indirectly for the use we make of it. Our reasons for choosing a scientific creed will probably be wrong; we cannot hope to do better always than Newton and Huygens. But perhaps we can do something with it which will be good and will last. It may contribute also to the general peace if we remember that our hypotheses are made, in the first instance, for our own personal use, and that we have no justification for demanding that others shall adopt the means which we find most convenient in the modelling of our own ideas.

\section{UNIVERSITY AND EDUCATIONAL INTELLIGENCE.}

Cambridge.-The professor of anatomy has reappointed Dr. W. L. H. Duckworth to be senior demonstrator of human anatomy for five years from January I, I9I3, and Mr. D. G. Reid to $b \in$ an additional demonstrator of human anatomy for the same period.

The Quick professor of biology has reappointed $\mathrm{Mr}$. C. Warburton to be demonstrator in medical entoNO. 2255 , VOL. 90] mology as from October I, I912, to September 30 , I9I5.

The managers of the Balfour Memorial Fund give notice that the Balfour studentship will be vacant March 25. The names of applicants, together with such information as they may think desirable, should be sent on or before January $3^{I}$ to the secretary, Prof. J. Stanley Gardiner, Zoological Laboratory, Cambridge.

OXFORD.-The master and fellows of University College intend to proceed, in the course of the Hilary Term, I9I3, to the election of a fellow qualified to take part in the educational work of the college as prælector, with special reference to the chemistry schools, provided that a candidate suitable to the requirements of the college presents himself. Candidates must have taken a degree in a university of the United Kingdom or of the British Dominions beyond the Seas, and be unmarried. A stipend of at least $350 l$. per annum, including the emoluments of the fellowship, will be assigned to the fellow and prælector, so appointed, from the first, with prospective rise of salary proportionate to nature and length of service. The prælector in chemistry will not be precluded from undertaking further work in the University, outside the college, subject to the consent of the master and fellows from time to time. Candidates are requested to forward to the master of University College, on or before January $3 \mathrm{I}, \mathrm{I} 9 \mathrm{I} 3$, the following documents:-(r) A signed application setting forth the candidate's qualifications, and any evidence (such, e.g. as original work) which he may desire to lay before the electors; (2) three, and not more than three, testimonials from independent sources in his favour.

Prof. R. M. Burrows, professor of Greek in the University of Manchester, bas been appointed principal of King's College, London, in succession to the Rev. Dr. A. C. Headlam.

THE fifth annual dinner of old students of the Royal College of Science, London, will be held at the Cafe Monico, Shaftesbury Avenue, on Saturday, January 25. The president of the Old Students' Association (Sir William Crookes, O.M., F.R.S.) will preside, and the guests will include Sir Alfred Keogh, K.C.B.. Sir Henry Miers, F.R.S., Sir Robert Morant, K.C.B., Lieut.-Col. Sir David Prain, C.I.E., Sir Amherst Selby-Bigge, K.C.B., Dr. R. T. Glazebrook, F.R.S., and Dr. H. Frank Heath, C.B. Tickets may be obtained on application to $\mathrm{Mr}$. T. L.1. Humberstone, secretary of the Old Students' Association, 3 Selwood Place, South Kensington, S.W.

THE recently established University of Hong Kong is making rapid strides in the development of its various faculties, and attention is at present being specially directed to the provision of facilities for the practical study of pure and applied science. In an address delivered to the Institution of Engineers and Shipbuilders of Hong Kong last November, Prof. C. A. M. Smith, professor of engineering in the new University, made an eloquent appeal to men of wealth to assist in the important work of training Chinese students in modern science. "In Hong Kong," he said, "we wish to train men who know the East to develop China's natural resources. For that development they must obtain machinery-if we do our work aright we shall secure a market for those who are at home, and provide greatly increased freightage for the shipping to this port." Later he continued:"We require at once machines for demonstration and experimental purposes. We want to equip laboratories for testing the materials of construction, such 